\title{
Sintaksis in Duits-onderrig: Die plasing van die onderwerp1
}

\section{E.C. Steyn}

In spite of strong similarities between German and Afrikaans syntax, there are also considerable differences, such as the positioning of the subject, which frequently appears much later in German sentences than in Afrikaans. This is evident, for example, in the comparison of a few parallel texts. An empirical investigation showed that the deferment of the subject undeniably creates problems for Afrikaans speaking students learning German. They find sentences with a deferred subject difficult to understand and find it even more difficult to construct their own sentences in this way. A few practical suggestions for teaching methods aimed at resolving these difficulties are presented here.

Ten spyte van sterk ooreenkomste tussen die Duitse en Afrikaanse sintaksis bestaan daar ook wesenlike verskille, soos bv. ten opsigte van die plasing van die onderwerp, wat in Duitse sinskonstnuksies dikwels later verskyn as in Afrikaans. Dit blyk onder andere uit die vergelyking van 'n paar parallelle tekste. ' $n$ Empiriese ondersoek het getoon dat hierdie vertraging van die onderwerp vir Afrikaanssprekendes wat Duits leer, heelwat probleme skep. Hulle vind dit moeilik om sinne met ' $n$ vertraagde onderwerp te verstaan en nog moeiliker om self sulke sinne te konstrueer. Enkele praktiese wenke word aan die hand gedoen om hierdie probleme deur doelgerigte onderrig te bekamp.

\section{INLEIDING: VERSKILLE TUSSEN DUITS EN AFRIKAANS}

Die noue verwantskap van Afrikaans en Duits, veral wat die sinsbou betref, is algemeen bekend. Daar bestaan egter op sintaktiese gebied ook wesenlike verskille tussen dié twee tale wat in die onderrig van Duits in Suid-Afrika nie buite rekening gelaat mag word nie. Hierdie verskille val veral op wanneer daar onderskei word tussen sinskonstruksies wat nie noodwendig foutief is nie en dié wat gebruiklik of stilisties aanvaarbaar is. In feitlik elke Duitse teks kom daar sinne voor waarvan die woordorde, of selfs die hele konstruksie, radikaal van Afrikaans verskil. Sodra 'n Afrikaner hom in 'n Duitse milieu begeef, word hy met sulke konstruksies gekonfronteer:

'n Aankondiging op die Hamburgse stasie:

1 Auf Gleis 8 fährt ein der Schnellzug aus München.

'n Kennisgewing in ' $n$ wagkamer oor 'n misdadiger wat ontsnap het:

1 Geldelike bystand gelewer deur die Instituut vir Navorsingsontwikkeling vir hierdie navorsing word hiermee erken. Menings in hierdie artikel uitgespreek of gevolgtrekkings waartoe geraak is, is dié van die outeur en moet nie aan die Instituut vir Navorsingsontwikkeling toegeskryf word nie. 
2 Hinweise nimmt die Kriminalpolizei Wuppertal entgegen.

Naambordjies by toonbanke en in busse:

3 Hier bedient Sie FRAU SCHMIDT

4 Es fährt für Sie HERR MüLLER

Kry hy pos uit Duitsland, val verdere voorbeelde van hierdie aard hom op:

5 Frohe Weihnachten und ein gutes neues Jahr

wüschen Dir

Danie und Reini

Die feit dat sulke konstruksies vir 'n Afrikaanssprekende vreemd voorkom, is onder andere daaraan toe te skryf dat die onderwerp van die sin in Duits dikwels later as in Afrikaans verskyn, partykeer - soos in bogenoemde voorbeelde - eers reg aan die einde van die sin. Dit is byvoorbeeld die geval wanneer die voorwerp vór die onderwerp geplaas word. Maar nie net die voorwerp nie, ook 'n wye verskeidenheid van ander elemente kan in Duits die onderwerp op hierdie manier "vertraag". Weliswaar kom sommige konstruksies van dié aard ook in Afrikaans voor; oor die algemeen egter handhaaf Afrikaans - soos Engels - 'n meer grammaties-gebonde woordorde: omdat die werkwoord- en naamvalsuitgange soos hulle in Duits voorkom, in Afrikaans en Engels grotendeels ontbreek, word die onderwerp aan die begin van die sin óf redelik vroeg in die sin geplaas sodat sy funksie duidelik herkenbaar is. Die Duitse taal, aan die ander kant, het in hierdie opsig baie meer vryheid: die onderwerp, voorwerp en dies meer kan gewoonlik aan die naamvalsuitgange herken word en is gevolglik in ' $n$ mindere mate aan bepaalde posisies in die sin gebonde.

\section{VERGELYKING VAN ENKELE TEKSTE}

Dat Duits en Afrikaans in 'n groot mate van mekaar verskil wat die plasing van die onderwerp betref, blyk duidelik wanneer parallelle tekste in dié tale met mekaar vergelyk word. Vir hierdie doel is ' $n$ beperkte ondersoek aan die hand van die volgende uitgevoer:

Die eerste paar bladsye van hoofstuk twee uit "Kringe in 'n bos" (D. Matthee) en die Duitse vertaling daarvan deur G. Stege, "Unter dem Kalanderbaum"

Hoofstuk een van "Und wenn Gott wäre ..." (H. Thielicke) en die vertaling daarvan deur A. Bouwer, "En sê nou God bestaan ...?"

Handelinge 8 en 9 uit Die Bybel (1983) en Die gute Nachricht (1971).

Die woordorde van verskeie sinne het in die vertalings onveranderd gebly; ook in die Bybelvertalings is die woordorde van sommige sinne identies. Enkele sinskonstruksies is heeltemal gewysig, met die gevolg dat daar dan geen sinvolle vergelyking met die oorspronklike getref kon word nie. In die geheel is daar nogtans 96 vergelykbare sinne waar die onderwerp in die Duitse teks later verskyn as in die Afrikaans. In die Afrikaans, daarenteen, kom die onderwerp slegs 14 keer later as in die Duits voor (Steyn, 1990:109116). Hierdie gegewens is op ' $n$ uiters beperkte ondersoek gegrond, maar dui nogtans wat die posisie van die onderwerp betref, op 'n aansienlike verskil tussen die twee tale (Bylae 1).

Die volgende kom onder die 96 sinne voor waarin die onderwerp in Duits later verskyn as in Afrikaans (vergelykenderwys word ook die Engelse vertalings uit "Circles in a forest" en "Good News for Modern Man" bygevoeg): 
Die onderwerp word in die Duits vertraag deur die plasing van elemente van verskillende aard aan die begin van die sin:

6 Die Trauerfeier leitete Oom Johannes Pels ...

(Matthee 1987:29)

Oom Johannes Pels ... het die diens kom hou.

(Matthee 1984:19)

Uncle Johannes Pels ... held the service.

(Matthee 1985:32)

7 Philippus fand man in Aschdod wieder.

(Apg. 8, 40)

Filippus is later in Asdod aangetref.

(Hand. 8:40)

Philip found himself in Ashdod ...

(Acts 8:40)

8 ... und immer wieder kehrte der eine Satz ... wieder ...

(Thielicke, 1970:39) en een sin het altyd weer opgeduik ...

(Thielicke 1974:16)

9 Vierzehn Jahre alt war Saul, als er ...

(Matthee 1987:22)

Hy was veertien toe hy ...

(Matthee 1984:14)

Saul was fourteen when he ...

(Matthee 1985:25)

Die onderwerp word in die Duits vertraag deur die plasing van elemente van verskillende aard ná die werkwoord of voegwoord:

10 Wenn ... dainter das Antlitz des Vaters ... erscheint ... $\quad$ (Thielicke 1970:33)

As ... die gelaat van die Vader ... agter Hom sigbaar

word ...

(Thielicke 1974:11)

11 ... wurde auch die Mutter krank.

(Matthee 1987:22)

... het hul ma ook siek geword.

(Matthee 1984:14)

... their mother became ill too.

(Matthee 1985:25)

12 Was hülfe mir ... die ganze Geschichte ...

(Thielicke 1970:33)

Wat sou die hele geskiedenis ... my help ...

(Thielicke 1974:11

Omdat feitlik elke denkbare element gebruik kan word om 'n Duitse sin mee in te lei en omdat die meeste elemente met uitsondering van die werkwoord geen vaste posisie in bysinne of in hoofsinne met inversie het nie (Engel 1988:329), bestaan daar in Duits 'n wye verskeidenheid van moontlikhede om die onderwerp te vertraag. In Afrikaans is sulke moontlikhede meer beperk (vgl. die konstruksies 7 en 12) en aan moontlikhede wat wel bestaan, word nie noodwendig voorkeur verleen nie (vgl. konstruksie 11).

\section{BEGRIPSPROBLEME AS GEVOLG VAN 'N VERTRAAGDE ONDERWERP}

Die plasing van die onderwerp in Duits kan vir beide Afrikaans- en Engelssprekende studente aansienlike probleme inhou. Wanneer hulle Duits lees, gaan die presiese betekenis van baie sinne met ' $n$ vertraagde onderwerp by hulle verby, omdat hulle nie die grammatiese samehang van die sinsdele begryp nie. Dit is onder andere deur 20 Afrikaanssprekende Duits I- en Duits II-studente van die Randse Afrikaanse Universiteit 
bewys wat ' $n$ artikel uit die tydskrif "Scala" moes lees en dan enkele onderstreepte sinne moes vertaal. Waar daar ' $n$ vertraagde onderwerp voorgekom het, is daar in meer as $40 \%$ van die antwoorde probleme met die presiese betekenis ondervind, omdat die onderwerp in die eerste instansie nie geïdentifiseer kon word nie. Dit was onder andere by die volgende sinne die geval:

\section{An Bord begrüßt Sie Ihr Erster Offizier.}

("Scala" 89(1):15)

(40\% van die studente het nie op die morfologiese kenmerke ag geslaan nie en die voorwerp (Sie) vir die onderwerp aangesien.)

14 ... denn sie reizt die Möglichkeit, ...

("Scala" 89(1):16)

( $80 \%$ het die semantiese aspek buite rekening gelaat en gevolglik die onderwerp en voorwerp met mekaar verwar.)

15 Dem hohen Leistungsstandard der Lufthansa-Piloten gehen

entsprechend hohe Anforderungen an die Bewerber voraus. ("Scala" 89(1):16)

(Groot verwarring het by $65 \%$ van die studente voorgekom. Hulle het of "dem hohen Leistungsstandard" of "der Lufthansa-Piloten" of "die Bewerber" as onderwerp van die sin vertolk.)

\section{VERSKILLE TUSSEN DUITS- EN AFRIKAANSSPREKENDES BY DIE PLASING VAN DIE ONDERWERP}

Dit is dus nie verbasend nie dat Afrikaanse studente in Duitse stelwerk geneig is om die onderwerp te vroeg in die sin te plaas. Dit blyk uit 'n empiriese ondersoek waarby 100 Afrikaanse Duits I- en Duits II-studente van die Randse Afrikaanse Universiteit, die Universiteit van Pretoria en die Universiteit vsn die Oranje-Vrystaat betrokke was asook 'n kontrolegroep bestaande uit 100 sestien- en sewentienjarige hoërskoolleerlinge uit verskillende dele van Duitsland. Vir die doel van die ondersoek is 20 sinne waarin die onderwerp volgens die taalgevoel van die Afrikaanssprekende "vertraag" word, uit die tydskrifte "Scala" en "Jugendscala" gehaal (Bylae 2). Hulle is vir twee opdragte (A en B) met 10 sinne elk gebruik. Elke student/leerling het vir elke opdrag 'n blaai ontvang waarop die verskillende elemente van die oorspronklike sinne in blokke verskyn. Die opdrag was in albei gevalle om sinne met die gegewe elemente te maak en die regte vorm van die werkwoord te gebruik. By opdrag B, wat eers na $A$ uitgevoer is, was daar ' $n$ voorbehoud: die onderwerp (wat duidelik omraam is) moes nie aan die begin van die sin geplaas word nie. Vrae na die konteks, die konstruksies van voorafgaande sinne en dies meer is nie in ag geneem nie. Slegs kort voetnotas het na die artikel verwys waarop elke sin betrekking het (Bylae 3). Die antwoorde dui op ' $n$ aansienlike verskil tussen die twee taalgroepe wat die plasing van die onderwerp betref (Bylae 4). Slegs die belangrikste resultate word hier saamgevat:

\section{Opdrag A:}

In bykans $65 \%$ van die gevalle het die Duitse leerlinge die onderwerp aan die begin van die sin geplaas. Dit is in lyn met die bewering van taalkundiges soos Kromann (1973:142) en Engel (1988:191) dat 50\% - 60\% van alle Duitse sinne met die onderwerp begin. By die Afrikaanse studente is hierdie persentasie egter heelwat hoër: in $79 \%$ van die gevalle word die sin met die onderwerp ingelei. Dit behels 'n verskil van $14 \%$ tussen die twee groepe. Daarbenewens is dit by albei opdragte opvallend dat die studente elemente wat in Afrikaans selde indien ooit aan die begin van ' $n$ sin sou staan, slegs by wyse van die hoogste uitsondering in die eerste posisie geplaas het (Steyn 1990:118-125). 
Vergelyk die volgende ten opsigte van die aantal leerlinge/studente wat met dieselfde element as in die oorspronklike sin begin het:

\section{Oorspronklike sin}

\section{Duitse leerlinge}

18

19

16
Afrikaanse studente

B.5. Ihren 150. Geburtstag feiern in diesem Jahr die

traditionsreichen Borsig-Werke in Reinickendorf.
2

2

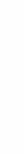


konstruksies soos deur die studente in bogenoemde opdragte saamgestel, stem ooreen met die Afrikaanse segswyse. Ofskoon sulke Duitse sinne grammaties korrek kan wees, is hulle semanties foutief wanneer hulle nie uitdrukking gee aan die juiste bedoeling nie. Hulle is dan nie net 'n toonbeeld van swak styl nie, maar mis ook die kommunikatiewe effek waarop die woordorde in Duits gemik is (Engel 1988:329).

\section{METODES OM PROBLEEM TE OORBRUG}

Ofskoon bogenoemde ondersoek slegs probleme van Afrikaanssprekende studente aan die lig gebring het, kan daar stellig verwag word dat Engelssprekendes dergelike probleme sal ondervind, daar ook Engels gekenmerk word deur ' $n$ vroeë plasing van die onderwerp (vgl. die konstruksies in 6,7,9 en 11). Die eerste stap om hierdie probleme te oorbrug, lê bepaald daarin dat daar reeds in die aanvangsonderrig baie meer aandag gegee word aan eiesoortige Duitse sinskonstruksies met 'n vertraagde onderwerp. Hiervan sou talle voorbeelde al uit die eerste lesse van beginnerskursusse aangehaal kon word. Daar word met enkeles volstaan:

16 Firma Neumann? Die kenne ich nicht.

(Schäpers 1980:12)

17 Hier 7207. Ist dort Herr Deppe?

(Neuner 1979:12)

18 Was ist denn das?

(Mebus 1987:10)

Vervolgens is ' $n$ bewusmaking van die groter vryheid ten opsigte van die woordorde wat die fleksiesisteem vir die Duitse taal inhou, noodsaaklik. Voorbeelde vir meer gevorderde studente kan vir dié doel uit tydskrifte en ander Duitse leesstof gehaal word. Wanneer die student ' $n$ beter insig in die prinsiep van die Duitse sinsbou verkry het, kan hy probeer om eie sinne op soortgelyke wyse saam te stel. Aanvanklik is oefeninge soos dié wat vir jong moedertaalsprekers gebruik word (Schorer 1967:19-21) aan te beveel, dit wil sê die konstruksie van sinne wat uit slegs twee elemente benewens die werkwoord bestaan. Die opdrag lui dan: Ruil die elemente om en besluit watter variasie verkieslik is. 'n Verskeidenheid van elemente kan in sulke oefeninge betrek word, veral dié wat in Afrikaans of Engels selde aan die begin van 'n sin sou staan, soos die direkte voorwerp (das langweilt mich / mich langweilt das - vgl. opdrag B.2.), byvoeglike bepalings (Sportschuhe sind sehr beliebt / sehr beliebt sind Sportschuhe - vgl. opdrag A.6.) en dies meer. As 'n verdere stap kan méér elemente betrek word met oefeninge wat gebaseer is op die patroon van opdrag A en B en behoort die student aangemoedig te word om met 'n verskeidenheid rangskikkingsmoontlikhede te eksperimenteer. Eers dan kan van hom verwag word om te ontdek dat die "vryheid" van die Duitse woordorde nie 'n willekeurige vryheid is nie, maar dat die aangewese woordorde vir 'n uiting in 'n bepaalde konteks juis ' $n$ baie spesifieke een - dikwels met 'n vertraagde onderwerp - is.

\section{BIBLIOGRAFIE}

Die Bybel. Nuwe vertaling. 1983. Kaapstad: Die Bybelgenootskap van Suid-Afrika.

Die gute Nachrichi. Das Neue Testament in heutigem Deutsch. 1971. Stuttgart: Württembergische Bibelanstalt.

ENGEL, U. 1988. Deutsche Grammatik. Heidelberg: Groos.

Goods News for Modern Man. The New Testament and Psalms in Today's English Version. 1971. New York: American Bible Society.

Jugendscala. Frankfurt am Main: Frankfurter Societäts-Druckerei. (verskeie uitgawes) 
KROMANN, H.-P. 1973. Zur Wortstellung in der Transformationsgrammatik des Deutschen. In: Linguistische Studien IV. Düsseldorf: Schwann.

MATTHEE, D. 1984. Kringe in ' $n$ bos. Kaapstad: Tafelberg.

MATTHEE, D. 1985. Circles in a forest. Penguin.

MATTHEE, D. 1987. Unter dem Kalanderbaum. Ins Deutsche übertragen von Gisela Stege. Bergisch-Gladbach: Bastei-Lübbe.

MEBUS, G. en A. Pauldrach, M. Rall, D. Rösler. 1987. Sprachbrücke I. Stuttgart: Klett.

NEUNER, G. en R. Schmidt, H. Wilms, M. Zirkel. 1979. Deutsch aktiv. Ein Lehrwerk für Erwachsene. Lehrbuch 1. Berlin/München: Langenscheidt.

Scala. Zeitschrift aus der Bundesrepublik Deutschland. Frankfurt am Main: SocietätsDruckerei. (verskeie uitgawes)

SCHäPERS, R. en R. Luscher, M. Glück. 1980. Grundkurs Deutsch. München: Verlag für Deutsch.

SCHORER, H. en A. Wiechmann. 1967. Lebendige Sprache. Ein Wegweiser in die Muttersprache. 5. und 6. Schuljahr. Frankfurt am Main/Berlin/Bonn/München: Diesterweg.

STEYN, E.C. 1990. Verzögerungsmomente im deutschen Satzbau. Ongepubliseerde M.A.-verhandeling. Randse Afrikaanse Universiteit.

THIELICKE, H. 1970. Und wenn Gott wäre ... Reden über die Frage nach Gott. Stuttgart: Quell.

THIELICKE, H. En sê nou God bestaan ...? Uit die Duits vertaal deur Alba Bouwer. Kaapstad/Johannesburg: Tafelberg. 


\section{BYLAE 1}

\begin{tabular}{lcc} 
& $\begin{array}{c}\text { Aantal kere wat die } \\
\text { onderwerp in die } \\
\text { Duits later verskyn } \\
\text { as in die Afrikaans }\end{array}$ & $\begin{array}{c}\text { Aantal kere wat die } \\
\text { onderwerp in die } \\
\text { Afrikaans later verskyn } \\
\text { as in die Duits }\end{array}$ \\
\cline { 2 - 3 } Matthee 1984 en 1985 & 35 & 1 \\
Thielicke 1970 en 1974 & 34 & 7 \\
Handelinge 8 en 9 & 27 & 6 \\
\hline Totaal & 96 & 14 \\
\hline
\end{tabular}

\section{BYLAE 2}

Die volgende sinne uit "Scala" (Sc) en "Jugendscala" (Js) is vir die ondersoek gebruik: A:

1. Übrig bleibt nur der Abfall.

2. Immer sind Zivilbeamte unterwegs.

3. Im Münchner Olympiastadion findet am 25. Juni das Endspiel statt.

4. 356000 Quadratmeter groß ist das Bavaria-Filmstudio in Geiselgasteig nahe bei München.

5. Eine Flußinsel im Rhein hat der Kunstsammler Karl-Heinrich Müller zu neuem Leben erweckt.

6. Sehr beliebt sind zum Beispiel "adidas"-Sportschuhe.

7. Auf Almen wird aus frischer Milch Bergkäse gewonnen.

8. Liebevoll restauriert wurden viele Fassaden.

9. Auch aufs Pferd wagen sich die Schüler.

10. Zurück bleiben viele ... kleine Lebewesen aus dem Meer. 
B:

1. Am Sonntagmorgen früh um sechs beginnt in St. Pauli der Fischmarkt.

(Js 87(2):33)

2. Irgendwie langweilt mich das.

(Js 87(4):10)

3. Wie in einem See spiegelt sich der Wolkenhimmel in der Fassade des Hochhauses.

(Sc 87(4):22)

4. Bei den Berlinern außerordentlich beliebt ist der Botanische Garten in Steglitz.

(Sc 87(3):15)

5. Ihren 150. Geburtstag feiern in diesem Jahr die traditionsreichen Borsig-Werke in Reinickendorf.

(Sc 87(3):35)

6. Am Aschermittwoch war für Harald Toni Schumacher alles vorbei.

(Js 87(4):11)

7. Dort verwandeln sich jedes Jahr im September die straßen in eine Galerie aus bunten Bildern.

8. Kabarett können eigentlich nur Schüler und Studenten machen. (Js 87(2):17)

9. Auf dem Eisbach im Englischen Garten fällt Wassersportlern ständig Neues ein.

(Sc 87(5):32)

10. Im Park in der Nähe vom Stadtplatz konnten sich die Einwohner von Ulm die bunten Fluggeräte ansehen. 
BYLAE 3A:

\begin{tabular}{|l|l|l|l|}
\hline bleiben & übrig & der Abfall & nur \\
\hline
\end{tabular}

\begin{tabular}{|l|l|l|l|}
\hline sein & immer & unterwegs & Zivilbeamte \\
\hline
\end{tabular}

\begin{tabular}{|l|l|l|l|}
\hline stattfinden & am 25. Juni & im Münchener Olympiastadion & das Endspiel \\
\hline
\end{tabular}

\begin{tabular}{|c|l|c|}
\hline sein & $\begin{array}{l}\text { das Bavaria-Filmstudio } \\
\text { in Geiselgasteig nahe bei München }\end{array}$ & 356000 Quadrameter groß \\
\hline
\end{tabular}

\begin{tabular}{|l|l|l|l|}
\hline erwecken & zu neuem Leben & $\begin{array}{l}\text { der Kunstsammler } \\
\text { Karl-Heinrich Müller }\end{array}$ & Eine Flußinsel im Rhein \\
\hline
\end{tabular}

\begin{tabular}{|l|l|l|l|}
\hline sein & sehr beliebt & "adidas"-Sportschuhe & zum Beispiel \\
\hline
\end{tabular}

\begin{tabular}{|l|l|l|l|}
\hline gewinnen & aus frischer Milch & auf Almen & Bergkäse \\
\hline
\end{tabular}

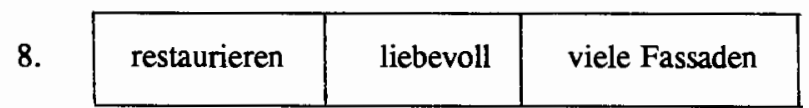

\begin{tabular}{|l|l|l|l|}
\hline sich wagen & auch & aufs Pferd & die Schüler \\
\hline
\end{tabular}

\begin{tabular}{|l|l|l|}
\hline bleiben & zurück & viele kleine Lebewesen aus dem Meer \\
\hline
\end{tabular} 
1. Art. Frankfurter Markt (Sc 2/88, S.25)

2. Art. und Bild: Nachtleben und Polizeikontrolle, Frankfurt (Js 5/82, S.12)

3. Art. Faßballmeisterschaft; Bild: Olympiastadion (Sc 2/88, S.18)

4. Art. Bavaria-Filmstudio (Js 4/82, S.18)

5. Art. Kunstinsel Hombroich (Sc 2/88, S.58)

6. Art. und Bild: Kleidung der Jugend in Ost-Berlin (Js 1/87, S.22)

7. Art. Bayern; Bild: Bauer mit Käse auf Alm (Sc 5/87, S.38)

8. Art. und Bild: Friedrichstadt mit alten Häusem (Sc 2/87, S.53)

9. Art. Blindenstudienanstalt in Marburg; Bild: Schüler auf Pferd. (Sc 4/87, S.51)

10. Art. und Bild: das Watt bei Ebbe (Js 3/86, S.15) 
BYLAE 3B:

1.

\begin{tabular}{|l|l|l|l|}
\hline beginnen & $\begin{array}{l}\text { am Sonntagmorgen, } \\
\text { früh um sechs }\end{array}$ & in St. Pauli & der Fischmarkt \\
\hline
\end{tabular}

2.

\begin{tabular}{|l|l|l|}
\hline langweilen & irgendwie & das \\
\hline
\end{tabular}

3.

\begin{tabular}{|l|l|l|l|}
\hline $\begin{array}{l}\text { sich } \\
\text { spiegeln }\end{array}$ & $\begin{array}{l}\text { wie in } \\
\text { einem See }\end{array}$ & $\begin{array}{c}\text { in der Fassade } \\
\text { des Hochhauses }\end{array}$ & der Wolkenhimmel \\
\hline
\end{tabular}

4.

\begin{tabular}{|c|l|l|l|}
\hline sein & $\begin{array}{l}\text { außerordentlich } \\
\text { beliebt }\end{array}$ & $\begin{array}{l}\text { bei den } \\
\text { Berlinern }\end{array}$ & $\begin{array}{l}\text { der Botanische Garten } \\
\text { in Steglitz }\end{array}$ \\
\hline
\end{tabular}

5.

\begin{tabular}{|c|c|c|c|}
\hline feiern & in diesem Jahr & $\begin{array}{c}\text { die traditionsreichen } \\
\text { Borsig-Werke in Rdorf }\end{array}$ & $\begin{array}{c}\text { ihren } 150 . \\
\text { Geburtstag }\end{array}$ \\
\hline
\end{tabular}

6.

\begin{tabular}{|l|l|l|l|l|}
\hline sein & vorbei & am Aschermittwoch & alles & $\begin{array}{l}\text { für Harald Toni } \\
\text { Schumacher }\end{array}$ \\
\hline
\end{tabular}

7.

\begin{tabular}{|l|c|c|c|}
\hline $\begin{array}{l}\text { sich } \\
\text { verwandeln }\end{array}$ & $\begin{array}{c}\text { in eine Galerie } \\
\text { aus bunten Bildern }\end{array}$ & $\begin{array}{c}\text { jedes Jahr } \\
\text { im September }\end{array}$ & dort die Straßen \\
\hline
\end{tabular}

8.

\begin{tabular}{|c|c|c|c|c|}
\hline $\begin{array}{c}\text { machen } \\
\text { können }\end{array}$ & eigentlich & nur & Schüler und Studenten & Kabarett \\
\hline
\end{tabular}

9.

\begin{tabular}{|c|c|c|c|c|}
\hline einfallen & ständig & $\begin{array}{l}\text { auf dem Eisbach } \\
\text { im Englishen Garten }\end{array}$ & Neues & Wassersportlern \\
\hline
\end{tabular}

10.

\begin{tabular}{|l|l|l|l|}
\hline $\begin{array}{l}\text { sich } \\
\text { ansehen können }\end{array}$ & $\begin{array}{l}\text { im Park in der Nähe } \\
\text { vom Stadtplatz }\end{array}$ & $\begin{array}{l}\text { die Einwohner } \\
\text { von Ulm }\end{array}$ & $\begin{array}{l}\text { die bunten } \\
\text { Fluggeräte }\end{array}$ \\
\hline
\end{tabular}

1. Art. Hamburg; Bild: Fischmarkt (Js 2/87, S.33)

2. Art. Kunst (Js 4/87, S.10)

3. Art. und Bild: Glasfassaden (Sc 4/87, S.22)

4. Art. Berlin; Bild: Bot. Garten (Sc 3/87, S.15)

5. Art. und Bild: Reinickendorf (Sc 3/87, S.35)

6. Art. Sport (Js 4/87, S.11)

7. Art. und Bild: Straßenmaler in Geldern (Js 6/86, S.9)

8. Art. Kabarett (Js 2/87, S.17)

9. Art. München; Bild: Eisbach im Eng. Garten (Sc 5/87, S.32)

10. Art. und Bild: Schneider von Ulm und seine Fluggerate (Js 4 u.5/86, S.17) 


\section{BYLAE 4}

Posisie van die onderwerp in die antwoorde van die Duitse leerlinge (D1) en die Afrikaanse studente (Ast) in vergelyking met dié in die oorspronklike sin:

\begin{tabular}{|c|c|c|c|c|c|c|c|c|c|c|}
\hline \multirow[t]{2}{*}{ A: } & \multicolumn{2}{|c|}{$\begin{array}{l}\text { aan die } \\
\text { begin van } \\
\text { die sin }\end{array}$} & \multicolumn{2}{|c|}{$\begin{array}{l}\text { nie aan die } \\
\text { begin nie, } \\
\text { maar vroeêr } \\
\text { as in die } \\
\text { oorspronklike }\end{array}$} & \multicolumn{2}{|c|}{$\begin{array}{c}\text { in } \\
\text { dieselfde } \\
\text { posisie }\end{array}$} & \multicolumn{2}{|c|}{$\begin{array}{l}\text { later as } \\
\text { in die } \\
\text { oorspronk- } \\
\quad \text { like }\end{array}$} & \multicolumn{2}{|c|}{$\begin{array}{l}\text { onvolledig/ } \\
\text { gewysig }\end{array}$} \\
\hline & D1 & Ast & Dl & Ast & D1 & Ast & D1 & Ast & D1 & Ast \\
\hline 1. & 6 & 11 & 82 & 87 & 12 & 1 & 0 & 0 & 0 & 1 \\
\hline 2. & 99 & 95 & 0 & 0 & 0 & 1 & 1 & 4 & 0 & 0 \\
\hline 3. & 44 & 81 & 13 & 12 & 43 & 7 & 0 & 0 & 0 & 0 \\
\hline 4. & 91 & 99 & 0 & 0 & 9 & 0 & 0 & 0 & 0 & 1 \\
\hline 5. & 84 & 84 & 0 & 2 & 14 & 13 & 2 & 0 & 0 & 1 \\
\hline 6. & 39 & 78 & 41 & 15 & 19 & 5 & 0 & 0 & 1 & 2 \\
\hline 7. & \multicolumn{10}{|c|}{ Nie in berekening gebring nie as gevolg van te veel foute en } \\
\hline 8. & \multicolumn{2}{|c|}{ wysigings } & & & & & & & & \\
\hline 9. & 75 & 87 & 19 & 8 & 6 & 2 & 0 & 0 & 0 & 3 \\
\hline 10. & 81 & 97 & 0 & 0 & 18 & 0 & $\mathbf{0}$ & 0 & 1 & 3 \\
\hline & 519 & 632 & 155 & 124 & 121 & 29 & 3 & 4 & 2 & 11 \\
\hline
\end{tabular}


http://perlinguam.journals.ac.za

\begin{tabular}{|c|c|c|c|c|c|c|c|c|c|c|}
\hline \multirow[t]{2}{*}{ B: } & \multicolumn{2}{|c|}{$\begin{array}{l}\text { aan die } \\
\text { begin van } \\
\text { die sin }\end{array}$} & \multicolumn{2}{|c|}{$\begin{array}{c}\text { nie aan die } \\
\text { begin nie, } \\
\text { maar vroeeer } \\
\text { as in die } \\
\text { oorspronklike }\end{array}$} & \multicolumn{2}{|c|}{$\begin{array}{c}\text { in } \\
\text { dieselfde } \\
\text { posisie }\end{array}$} & \multicolumn{2}{|c|}{$\begin{array}{l}\text { later as } \\
\text { in die } \\
\text { oorspronk- } \\
\text { like }\end{array}$} & \multicolumn{2}{|c|}{$\begin{array}{l}\text { onvolledig/ } \\
\text { gewysig }\end{array}$} \\
\hline & D1 & Ast & $\mathrm{Dl}$ & Ast & D1 & Ast & D1 & Ast & D1 & Ast \\
\hline 1. & 0 & 3 & 23 & 80 & 74 & 16 & 0 & 0 & 3 & 1 \\
\hline 2. & 0 & 0 & 20 & 88 & 79 & 5 & 0 & 0 & 1 & 7 \\
\hline 3. & 0 & 0 & 2 & 38 & 64 & 46 & 33 & 15 & 1 & 1 \\
\hline 4. & 1 & 1 & 69 & 84 & 26 & 11 & 0 & 0 & 4 & 4 \\
\hline 5. & 0 & 1 & 84 & 98 & 16 & 1 & 0 & 0 . & 0 & 0 \\
\hline 6. & 0 & 0 & 10 & 93 & 90 & 6 & 0 & 0 & 0 & 1 \\
\hline 7. & 0 & 0 & 27 & 43 & 49 & 23 & 21 & 14 & 3 & 20 \\
\hline 8. & 0 & 0 & 63 & 71 & 32 & 13 & 2 & 1 & 3 & 15 \\
\hline 9. & 0 & 1 & 10 & 69 & 80 & 14 & 0 & 0 & 10 & 16 \\
\hline 10. & 1 & 0 & 11 & 56 & 76 & 25 & 4 & 2 & 8 & 17 \\
\hline & 2 & 6 & 319 & 720 & 586 & 160 & 60 & 32 & 33 & 82 \\
\hline
\end{tabular}

